\title{
The Strategy of Spatial Development of Russia: modernity and the legacy of the Soviet Settlement Doctrine
}

\author{
Mark Meerovich ${ }^{1, *}$ \\ ${ }^{1}$ Irkutsk National Research Technical University, Lermontova str., 83, Irkutsk, Russia \\ ${ }^{1}$ Scientific Research Institute of Theory and History of Architecture and Urban Planning, branch of the \\ Central Institute for Research and Design of the Ministry of Construction and Housing and Communal \\ Services of the Russian Federation, 111024, Dushinskaya str., 9, Moscow, Russia
}

\begin{abstract}
The article criticizes the strategy of spatial development of Russia, legally stated in the government document "The Strategy of Spatial Development of the Russian Federation for the period up to 2030. A Draft Concept", released by the Ministry of Economic Development (2016). The author argues that the Strategy only states the existing situation, but does not enumerate a set of measures that are to be undertaken to strengthen the possibility of implementing any development scenario, and does not outline the ways of making assumptions a reality. The paper proves that the postulates of the Soviet settlement doctrine and urban planning theory still deeply impact the contemporary theory and practice of territorial planning.
\end{abstract}

The influence of the postulates of the Soviet settlement doctrine and urban planning theory, practically implemented in the USSR, on the contemporary theory and practice of territorial planning, has not been the subject of the focused analysis, despite the fact that they (even in the conditions of those cardinal changes that have undergone in the political structure of Russia) still in the most serious way predetermine the conceptual strategic and theoretical and methodological concepts of social, economic, production, and other mechanisms of development of the resettlement system in the Russian Federation, and the elaboration of specific measures to manage the country's spatial and economic development. The answer to the question: "To what extent do modern approaches to the development of a strategy for the formation of the settlement system and its individual components remain a captivity of the theory of socialist settlement and socialist city, and to what extent are they capable of opposing it?" is relevant and important for the development of both the theory itself, and the effectiveness of the practical design and implementation of its postulates.

This topic has a serious scientific background. First of all, we should mention the works devoted to the initial stage of the formation of the theoretical foundations of the Soviet urban planning, the works of: M. Astafieva-Dlugach, M. Barkhin, V. Belousov, Yu. Bocharov, V. Glazychev, G. Gradov, A. Gutnov, A. Ikonnikov and others. The Soviet urban and district

*Corresponding author: memark@ inbox.ru 
planning of 1930s-1950s (before Khrushchev's reform) and of 1950s-1990s (before Perestroika) were comprehensively analyzed by V. Vladimirskii, V. Neimark, E. Leizerovich, E. Pertzik, G. Yusin, V. Lyubovnyi, Yu. Kosenkova, O. Orelskaia, S. Dukhanov, E. Konysheva, and G. Yakovleva. Fundamentals of urban planning design of the period of the 1970s-1980s are outlined in the educational and methodological literature authored by L.N. Avdotin, I.G. Lezhava, I.M. Smoliar, Z.N. Yargina, Ya.V. Kositskii, E.M. Mikulina and others. Changes in the planning doctrine from the quarter to the neighborhood approach in the period of the Khrushchev's reforms were analyzed in the works of N. Krainiaia, Yu. Kosenkova, and in collections of scientific materials [1]. Some aspects of the settlement theory and the practices of the Soviet period were studied by the specialists from the related fields of knowledge: L. Borodkin, N. Bugai, M. Verner, V. Zemskov, N. Gushchin, N. Ivnitskii, S. Krasilnikov, S. Maximov, N. Platunov, N. Simonov, L. Suvorova, etc. The urban policy of modern Russia and the features of the legislative regulation of modern urban planning are analyzed in the textbooks and monographs of A. Krashennikov. Methodological approaches to the study of the processes of formation and regulation of the agglomerations, related to the location of industry and inseparably connected with it, are described in the works of Yu. Bocharov, L. Vavakin, E. Veinberg, M. Vilner, V. Vladimirov, N. Vlasova, L. Gerzberg, P. Davidenko, V. Davydovich, A. Zholkov, V. Zuev, V. Koliasnikov, G. Lappo, I. Lezhava, V. Lyubovnyi, V. Pokshishevskyi, E. Pertsik, Ya. Silin, I. Smoliar, N. Naimark, G. Filvarov and many other contemporary scientists.

However, despite the abundance of works detailing the individual aspects of the topic considered in this paper, the elaboration of the strategy of Russia's spatial and economic development largely extends the postulates of the Soviet settlement doctrine.

In 2016, the Ministry of Economic Development of the Russian Federation developed a draft concept of the Strategy of spatial development of the Russian Federation for the period up to 2030 [2]. The analysis of this document makes it possible to reveal the extent to which the basic postulates of the Soviet urban planning theory, despite radical social and political changes that have undergone in Russia, are continuing influencing the current theoretical, and normative and methodological principles of designing the system of the country's spatial and economic development, and the view of the role and perspectives of the development of Russian cities and local settlement systems.

The strategy quite accurately lists the challenges posed by the current situation. The main one is an unprecedented centripetal vector, which in recent decades has been most visibly manifested at the federal level - in the form of a sharp increase in Moscow's economic role in all key indicators of economic development. Similar centripetal processes are also characteristic (albeit to a much lesser extent) for some constituent entities of the Russian Federation, where such an increase in the economic and political role of regional capitals and elites occurred [1]. The same process has also manifested itself in some municipalities that have large cities as their centers, which, under the conditions of the new market economy, happened to be successfully located on the key trade and transport routes and managed to use these advantages for their development.

The Program provides a fairly accurate analysis of not only the current state, but also of negative trends: a) demographic "desertification" of the country's territory; increase in the imbalance of the agglomeration spatial framework of the settlement system, and economic degradation of a significant part of the territory of Russia [1] (the population of the Center, South and North-West of Russia is increasing, while the Ural-Volga, Siberia, the Far East and especially the European North are losing the population [1]), which leads to increasing spatial and economic disproportion - the territorial squeezing of the economic space and the sliding of its "condensed" zone to the Center and the North-West, and to a substantial increase in the density of the economic activity on the limited territory of this macro-zone (5\% of the 
total territory of the country, more than a third of the country's population, more than $42 \%$ of the gross regional product, about $37 \%$ of revenues to the budget system of the Russian Federation, and $32 \%$ of total investment) and as a result: b) compression of the previously developed space (both in rural areas and in industrial zones of large, medium and small cities), c) the decline in the operational load on a number of sections of the network of railways and highways, which is extremely unevenly developed [3], d) economic compression of the space of city centers (federal, regional and municipal levels), e) spatial expansion of large cities to rural areas, as well as spontaneous filling of urban "fabric" and interurban spaces with new construction [1]; f) unification of the existing Russian legislation in the sphere of spatial development - the monotony of norms and rules, excluding local specificity and, as a result, its complete absence in the design (this aggravates the gap between Russian city centers and periphery, as it hinders the initiatives of local communities "from below", depriving both local authorities and business of opportunities for creative, innovative formation of the design options that are optimal and precisely selected specifically for local conditions) [1]; g) insufficiency of resources generated on the territories of the majority of constituent entities of the Federation for self-development [1]. (The macro-zone of the Center and the North-West of Russia includes all the constituent entities of the Russian Federation that form part of the Central Federal District, as well as a number of subjects of the Russian Federation belonging to the North-West Federal District (Kaliningrad, Leningrad, Novgorod, Pskov regions, and St. Petersburg)).

However, nothing fundamentally new has been proposed as a strategic way out of this situation, in comparison with the Soviet doctrine that was formed in the framework of the first (Stalin's) industrialization program, namely: a) the formation of new resource production zones; b) the placement of "socialist industry" in the areas of territorial development, indicated in the first five-year plans; c) development of the military-industrial complex; and d) the formation of transport infrastructure.

Soviet industrialization was based on the planned creation of the concentration points of production and the population tied to them, evenly distributed throughout the country, in order to smooth out the imbalance in the extremely unequal density of the population, and respective unequal economic development. Urbanization, within the framework of such a model, ensured the formation of a network of industrial-settlement-energy nuclei of new resettlement. The urban planning measures were based on reducing to minimum the uncontrolled movements of the able-bodied population throughout the country, which was achieved by its linking to the places of work with a complex of nationwide state measures, such as registration, distribution of the minimum living standards attached to the workplace, legislative prohibitions of unauthorized dismissal, etc., that is, by the specially formed labormobilization and military-mobilization organization of the Soviet society $[4,5]$. The natural migrations that broke this "planned-coercive" urbanization, were de facto prohibited [6], and the need for labor resources at the construction sites of new plants was provided with artificial measures for the movement of labor force [7, 8].

The "Strategy of Spatial Development of the Russian Federation" does not contain any indication on any nationwide measures that should be taken today to increase the attractiveness of life in the rural areas or small settlements, in conditions when measures of prohibition or restrictions on natural migrations are not applicable, and on which means of the state protectionism should be used to increase motivation of the population to stay in the places with unfavorable climatic factors.

In the orientation of Stalin's urbanization to the formation of a network of new mediumsized cities (with their planned conversion into large ones), the existing small towns unwittingly found themselves in conditions of not only losing their status as local administrative and management centers, but also in a situation of the outflow of population, 
as they were sources of relatively skilled proletariat, artificially moved to the construction sites of the five-year plans. To overcome this negative tendency and to preserve this kind of settlements as one of the basic foundations of the Soviet resettlement doctrine, a decision was made in the USSR at the nationwide level to maintain the production potential of historic settlements. This was due to the fact that the industrial enterprises that existed in these places were included in the industrialization program, being modernized and reoriented for militarydefense purposes, and by erecting new civil-military production facilities in these cities. In addition, the viability of historical settlements was maintained as a result of administrative measures to merge, both territorially, and administratively, several workers' settlements together, or to include them in the zone of influence of a new large industrial city. That, despite the nationwide strategy of extracting labor resources from the villages (the collectivization program) and from the existing small populated areas (artificial migrations) to fill the workforce of the industrial construction sites, a system of measures to support the traditional settlement layer was implemented. We have to note that in fact, the development of the New General Scheme of Settlement on the Territory of the RSFSR in the 1970s and 1980 s, relying on the doctrine of formation of the group systems of populated areas (B. Horev, G. Lappo, etc.) was based on the same methodological principles. And the General scheme of settlement on the territory of the Russian Federation that was developed by Giprogor in 1993-1994, was also de facto based on this methodology. The General Scheme formed a structure of closely interconnected urban and rural settlements of various sizes and different economic profiles, the functional stability of which was provided by the developed territorial production links, general engineering infrastructure, and the unified network of public centers of social services and recreation.

The Strategy of the spatial and economic development of Russia up to 2030, fixing the tendency of the constant shift of the population of the country from the east to the west and from the north to the south typical for the last decades, and pointing out the depopulation of some fragments of the territory caused by natural migrations, offers no system of countermeasures, and no conceptual approaches to resuscitation of historical small settlements. There are no any proposals for stabilizing the viability of small towns, including single-industry towns that emerged during the first and second waves of industrialization, which today are also catastrophically losing their labor resources.

The concept of strategic development of modern Russia, in full accordance with the concept of the Soviet period, suggests: 1) the development of the existing and the deployment of new resource extraction zones with the aim of "activating ... the sale of fuel, energy and other raw materials on the global market". The direction of "development connected with the export of raw materials, especially fuel and energy sources, up to 2030, is fixed in a number of sectoral strategic documents and international agreements", which will inevitably determine the development of the regions of traditional production, as well as the growth and infrastructure development of new mining regions [1], that, we have to note, consolidates and strengthens the "resource" economy, and not the "innovative" one; 2) the development of the military-industrial complex with the hope that the regions, in which military enterprises are located, "in the future would be able to become centers for the generation and implementation of innovations" [1]; 3) "the realization of the transport and transit potential" [1], that, unlike the Soviet period, not so much focused to meet the country's own needs, but to the transportation of the third-party goods - transit cargo (we will note that, in this case, "the development will receive large transport centers and port regions on the south, west and east of the country connected with servicing of the export goods"[1], rather than a finely dispersed network of transport communications, capable of linking settlements of all scales, functions and levels). The only difference is that instead of placing a new industry in the new areas of territorial development, it is proposed: 4) to strengthen "international cooperation and the 
development of integration processes in the Eurasian space" [1] (that, as a result of a more dense inclusion in the global division of labor, weakens the independence and selfsufficiency of the development potential of the country).

In the proposed Strategy, the principles (factors) for placing new production are, in fact, the same as in the Soviet period: a) raw materials, b) labor resources, c) marketable resources, d) transport, and e) energy. The only difference is that in the period of Stalin's industrialization and its second wave - the Khrushchev's one, all these factors (except for the raw materials) were created artificially - the energy hubs were built on empty places in the development zones, transport communications also came there, and labor resources moved to the developing territories in various ways and were assigned to permanent residence, etc. [1]. This is why the Strategy says today that "the vast space of the country has become a catalyst for its development in the Soviet era" [1]. But, alas, the Strategy still does not answer the question: due to what reasons, these advantages, historically created in the Soviet period, in contemporary Russia became "a brake and a burden of the economic development ..." [1]. It also remains unclear why the Strategy is not able to offer concrete ways to eradicate these causes and overcome the consequences.

With regard to the location of "the new types of industry (based on biotechnologies, modern electronic industry, knowledge-intensive business services, etc.)" and new activities, it is propagandistically proclaimed that in their deployment they will be guided "by new factors related to innovation, knowledge flows, entrepreneurial energy, venture capital, personnel qualification"'[1]. But in the Strategy, these sonorous terms are not backed by any means of achievement - specific legislative, economic, managerial, etc. measures or a system of specific actions - that means that they will remain only "correct formulations", which will continue to be implemented based on: a) raw materials, b) labor resources, c) marketable, d) transport, e) energy, etc. traditional factors. Specifically, inter alia, this is why that, unlike "intellectual types of economic activity", which mainly function in the Internet space and are "transported" through computer networks, for the modern high-tech industries, the key factors in the placement of the production facilities are still the factors of availability of: 1) natural resources, 2) transport connectivity, 3) cheap energy, 4) sales markets, and 5) concentrated skilled labor resources.

The Strategy states that the contemporary system of resettlement on the territory of the Russian Federation is formed by the settlement systems of six major hierarchical levels, including: the first level - settlements and urban districts, within which there are several settlements; second level - municipal districts with several settlements; third level - interdistrict settlement systems (urbanized territories), including agglomerations formed within the boundaries of one constituent entity of the Russian Federation; the fourth level - regional settlement systems, formed within the boundaries of constituent entity of the Russian Federation; the fifth level - interregional settlement systems within the boundaries of the constituent entities of the Russian Federation (krai, oblast), in which autonomous territories are formed, as well as interregional settlement systems within the boundaries of two or more constituent entities of the Russian Federation; the sixth level is the system of resettlement of the nationwide level, the list of which includes: Moscow, St. Petersburg, Sevastopol, Rostovon-Don, Stavropol, Nizhny Novgorod, Ekaterinburg, Novosibirsk, Khabarovsk, Voronezh, Krasnodar, Volgograd, Kazan, Ufa, Samara, Perm, Chelyabinsk, Omsk, Krasnoyarsk, Irkutsk, and Vladivostok [1].

The system of resettlement is understood as the aggregate of cities, settlements, rural settlements of different size and functional type located on the territory (on a part of the territory) of the Russian Federation, united with system-forming social and economic links, transport and other communication networks [1]. 
The urbanized region is an urbanized territory, the spatial framework of which is formed by the compact groups of neighboring agglomerations and the transport communications of federal and interregional significance that connect them. The indicative parameters of the urbanized region are the following: the total population of agglomerations is 2.5 and more million people, the number of agglomerations is 3 or more, including 1 agglomeration with a population of more than 500 thousand people, the distance between the centers of neighboring agglomerations is not more than $200 \mathrm{~km}$, the distance between the centers of the most faraway from each other agglomerations is not more than $500 \mathrm{~km}$. Territories that correspond to the concept of the urbanized region can be identified in the Central, Southern, Volga, Ural and Siberian federal districts. They occupy more than 5\% of the territory of Russia and more than $14 \%$ of the main settlement area, the total population of the urbanized regions can be estimated as 63 million people. They comprise almost half of all agglomerations with a total population of more than 54 million people, including 12 of 20 cities belonging to the upper sixth level of the hierarchy of the settlement systems on the territory of the Russian Federation [1].

The agglomeration is an urbanized area, which is a settlement system, consisting of a city that is not part of another agglomeration - a center of the agglomeration with a population of typically 100 or more thousand people and the external (suburban) zone with a population of 10,000 or more people, which boundaries are determined by regular and intensive labor, production, administrative and business, trade, transport, logistics, recreational and other connections of the city center and the populated areas of the outer zone. The actual agglomeration boundaries (not tied to the administrative ones) as a rule correspond to the isochrone of 1.5 to 2.0 hours of transport accessibility to the center city [1].

The strategy fixes the fact that currently on the territory of Russia, there are 124 agglomerations that have formed or are being formed with a total population of about 85 million people (58\% of the total population of the country), occupying a total area of about 670 thousand sq. $\mathrm{km}$. (less than $4 \%$ of the entire territory of Russia or about $11 \%$ of the territory belonging to the main strip of settlement). In these 124 agglomerations, the agglomerations of four levels are distinguished, depending on the population that includes: 17 agglomerations with a population of more than 1 million people each (more than 44 million people in total); 28 agglomerations with a population of 500 to 999 thousand people (a total of 19 million people); 45 agglomerations with a population of 250 to 499 thousand people each (more than 15 million people in total); 34 agglomerations with a population of 100 to 249 thousand people (a total is almost 6 million people). This network of agglomerations is extremely uneven and heterogeneous in the territorial aspect. Thus, in the European part of Russia (Central, North-Western, Southern, North-Caucasian and Volga Federal Districts, which together account for $23 \%$ of the country's territory), there are 87 agglomerations with a total population of almost 65 million people (44\% of the total population of Russia). In turn, in the Asian part of Russia (the Ural, Siberian and Far Eastern Federal Districts, which account for $77 \%$ of the country's territory), 37 agglomerations with a total population of about 20 million people are located (14\% of the total population of Russia, but more than half of the total population of the Asian part of the country).

The strategy is strong in its prognostic content. It confidently points out the emergence of "innovative valleys, industrial parks, special economic zones, etc." within the settlement period [1]. It suggests that: 1) the scale and rate of concentration of the population in the urbanized areas will increase - the total number of agglomerations will be reduced to 100115, while the structure of their network will change significantly [1]. In another scenario, which is also described in the Strategy, there may be "an accelerated development of 15-20 agglomerations ... and the creation of support and base development centers for strategically important regions connecting their centers with multimodal transport and logistical systems" 
[1]. And, probably, there will be "elimination of intra-regional center-periphery gaps" and liquidation of inter-regional disproportions" [1]. One of the scenarios, called "The Scenario of the polarized growth", is considered in the Strategy as the basis for the development of the country, since it is based on the allocation of certain regions as "the growth locomotives" (this approach is described in detail in "The Concept of the Strategy of Socio-Economic Development of the Regions of the Russian Federation" developed by the Ministry of Regional Development of Russia ten years ago, in 2005). The constituent entities of the Federation (the Khanty-Mansiysk Autonomous Okrug-Yugra, the Krasnodar Territory, the Republic of Tatarstan, the Sverdlovsk Region, the Yamal-Nenets Autonomous District, the Krasnoyarsk Territory, the Republic of Bashkortostan, etc., which in 2014 amounted for aggregate $51.6 \%$ of the total GRP), and urban agglomerations, as well as cities (Moscow and St. Petersburg) can be such "locomotives" [1].

However, at the same time, the Strategy only states the existing situation, but does not list a set of measures that must be applied to strengthen the realistic implementation of this scenario (or any other, that is not so clearly manifested, but is seen as the most preferable to achieve the desired future), and does not outlines the ways by which the assumptions can be converted into reality. Considering the options of further development of the situation, and models and scenarios, the Strategy does not provide answers to the questions about the measures by which it is possible to overcome the mentioned negative trends and through which it is possible to purposefully influence the situation, to achieve concrete results that is a priority from the point of view of the country's spatial and economic development. It does not say what conditions must be created in order to stimulate appearing these "innovative valleys, self-sufficient and cost-effective industrial parks and special zones".

In the Soviet epoch, in the conditions of centralized planning and state regulation of the economy, the spatial organization of various spheres of social and economic development and the structure of the territorial management logically coincided: spatial forms of economic development were purposefully combined with administrative boundaries [1]. In the event of the formation of new economic regions due to the emergence of new branches of the economy, existing administrative boundaries were reshaped accordingly (for example, Ivanovo and Kemerovo oblasts, which were carved out of former provinces and regions, emerged in connection with the formation of the integral regions, respectively, of the textile and coal industries). The strategy of the Ministry of Regional Development raises the issue of the need to abolish the rigid linking of the political and administrative structure and the management of the economy [1], of the need to revise approaches to the territorial organization of managing the country's socio-economic development, even addressing the existence of foreign experience of "flexible changes in agglomeration boundaries", depending on the change in the population and the "density" of economic processes. However, it does not mention any concrete measures to achieve this, except for proposals referring to the formation of new "administrative structures for coordinating socio-economic development (project administrations) on the territory of several constituent entities of the Russian Federation or several municipal entities within the same constituent entity of the Federation" [1], that is, the creation of additional administrative bodies with a completely unclear legislative status and rights.

It should be noted that the postulates of the Soviet settlement doctrine and the urban planning theory still impact the contemporary theory and practice of territorial planning. The cardinal difference between the approach to territorial planning and the management of the spatial and economic development of the Soviet period from today is only in the fact that today, the management of territorial development is based on the knowledge systems formed in various separate professional subject areas not closely connected with each other, such as economics, management, statistics, transport, etc. The idea of the situation in the cities and 
the system of resettlement is formed through these professional realities based on such indicators as incomes, the amount of budget expenditures, the volume of extracted raw materials, the kilometrage of its transportation, the volume of products produced, and so on. [9]. However, in these fragmentary "pictures", abstracted from the realities of being, the complex understanding of the laws of life and the activities of the population, the conditions and factors of its everyday life, the socio-cultural specifics of the existence of a single space of such a mega-organization as "a country" is absent. "Soviet science can be addressed with tough claims, accused in the falsification of statistics, dogmatism and utopianism, but in the Soviet institutions that developed settlement systems, spatial development schemes, spatial management strategies ... there were intelligent, knowledgeable people who, despite all the shortcomings of the Soviet system" [9] knew this holistic picture, and based on it their professionalism, formed research subjects and worked out solutions.

However, today, the mind and knowledge of individuals and even the intellectual capacities of large research teams are no longer capable of gathering together vast amounts of information and data. The theory of urban planning and the theory of settlement, the territorial planning and management of all levels, are facing the issue of digitalization and computer configuration of the arrays of diverse knowledge in those huge volumes that are collected and systematized in specific disciplines of the scientific knowledge [11]. Specialists of the Soviet period, who had mastered the methodology of the integrated approach in the decision-making, have almost completely left the sphere of professional activity, the system of education is not able to train new universal specialists, and in the domestic research and design daily life, there are still no needed information technologies and models of generalization and data processing.

\section{References}

1. Moscow Urban Forum, Archeology of the periphery (2013)

2. Ministry of Economic Development, The strategy of spatial development of the Russian Federation for the period up to 2030 Concept (Project) (Moscow, 2016)

3. I. G. Lezhava, Academia, 3, 84-92 (2017)

4. M. G. Meerovich, From city-gardens to sotsgorodam: the main architectural and urban concepts in the USSR (1917 - the first half of the 1930's), 114-118 (2016)

5. M. G. Meerovich, Project-Baikal, 24, 118-119 (2010)

6. M. G. Meerovich, Proceedings of the All-Russian Scientific Conference on Culturology, 92, 54-58 (2008)

7. K. L. Lidin, M. G. Meerovich, Proceedings of the All-Russian Scientific and Practical Conference, 180, 75-83 (2017)

8. M. G. Meerovich, Project-Baikal, 24, 87-93 (2010)

9. E. Grigorieva, A. Bokov, Project Baikal, 54, 41-43 (2017)

10. V. E. Volynskov, Academia, 3, 99-102 (2017)

11. V. E. Volynskov, Academia, Architecture, and Construction, 3, 99-102 (2017) 